\title{
MELAMPAUI OPOSISI BINER: \\ STUDI KOMPARATIF TENTANG THE THIRD FORCE, METAXU, DAN THE THIRD SPACE
}

\section{Hardiyan Triasmoroadi}

\author{
Pendeta Gereja Kristen Jawi Wetan (GKJW) \\ Email: hardiyan.triasmoroadi@gmail.com
}

\begin{abstract}
Binary opposition is a necessity in the context of identity contestation which puts forward arguments and loneliness to test truth claims. In responding to the binary opposition, some theoretical elaborations which pretended to go beyond binary opposition are emerged, as Richard Kearney's conception of metaxu, Homi K. Bhabha's construction of the third space, and Cynthia Bourgeault's proposal regarding the third force. Based on the writer point of view, these three theoretical constructions are effectivein breaking the deadlock. Therefore, the researcher elaborated and compared the main ideas and key conceptions of the third force, metaxu, and the third space, to further present some conclusion points as a theoretical contribution in underlying movement praxis that longs to transcend binary opposition.
\end{abstract}

Keywords: Binary Opposition, Binary System, Ternary System, Metaxu, the Third Space, The Third Force.

\begin{abstract}
Abstrak
Oposisi biner merupakan keniscayaan di tengah konteks kontestasi identitas yang mengedepankan adu argumentasi dan kesalingan untuk menguji klaim kebenaran. Dalam rangka merespons oposisi biner, muncul elaborasi-elaborasi teoretis yang berpretensi melampaui oposisi biner, sebagaimana konsepsi Richard Kearney mengenai metaxu, konstruksi Homi K. Bhabha tentang the third space, dan proposal Cynthia Bourgeault perihal thethird force. Saya berpendapat bahwa ketiga konstruksi teoretis tersebut mangkus dalam meretas kebuntuan. Dus, saya akan menguraikan dan mengkomparasi ide pokok serta konsepsi kunci dari the third force, metaxu, dan the third space, untuk selanjutnya menyajikan beberapa poin kesimpulan sebagai sebuah kontribusi teoretis dalam mendasari praksis pergerakan yang rindu untuk melampaui oposisi biner.
\end{abstract}

Kata kunci: Oposisi Biner, Binary System, Ternary System, Metaxu, The Third Space, The Third Force 


\section{PENDAHULUAN}

Ternary system ada dalam rangka melengkapi binary system. Cynthia Bourgeault menjelaskan bahwa di dalam the law of three keberadaan oposisi biner yang direpresentasikan oleh affirming factor dan denying factor, direspons oleh kehadiran the third force atau kekuatan ketiga yang memediasi dan merekonsiliasi prinsip ketegangan di antara keduanya. ${ }^{1}$ Third force atau kekuatan ketiga yang dimaksud adalah reconciling atau neutralizing factor, yang diperkenalkan oleh Cynthia Bourgeault melalui aturan three creates a fourth in a new dimension. ${ }^{2}$

Menariknya, di dalam diskursus epistemologis terdapat konstruksikonstruksiyang serupa dengan third force atau kekuatan ketiga, yakni metaxu ataujalan tengah (middle way), atau jalan ketiga (third way), yang dikemukakan oleh Richard Kearney. Selain metaxu, hibriditas sebagai third space, atau ruang ketiga yang digagas oleh Homi K. Bhabha, juga memiliki kemiripan dengan third force. Konsep hibriditas atau ruang ketiga Bhaba, kemudian dikembangkan dalam konteks teologi praktika oleh Christhoper Baker dan dalam konteks homiletika oleh Kwok Pui-lan. Dus, secara ringkas saya akan mengulas ide pokok dari the third force, metaxu, dan the third space, sekaligus pada saat yang sama membandingkan kemiripan serta perbedaan ketiga konstruksi tersebut.

\section{PEMBAHASAN}

\section{Third force}

Bourgeault, secara ringkas menjelaskan prisip dasar the law of three sebagai berikut. Pertama, dalam setiap kemunculan atau kehadiran sesuatu yang baru, senantiasa terdapat interaksi dari tiga kekuatan, yakni affirming, denying, reconciling/neutralizing. Kekuatan pertama ialah affirming, kekuatan kedua adalah denying, dan kekuatan ketiga ialah reconciling atau neutralizing. ${ }^{3}$ Namun kekuatan yang ketiga bukanlah produk dari dua kekuatan sebelumnya, sebagaimana pola Hegelian klasik (thesis, antithesis, synthesis), melainkan ketiganya setara tanpa ada yang mengatasi satu sama lain. Bourgeault mengilustrasikannya melalui skema yang saya konstruksikan di bawah ini: 


\begin{tabular}{|l|l|l|l|}
\hline First force & Second force & Third force & New arising \\
\hline Benih & Tanah & Matahari & Tunas \\
\hline Tepung & Air & Api & Roti \\
\hline Nukleus & Elektron & Medan elektromagnetik & Atom \\
\hline
\end{tabular}

Tabel 1

Kedua, pilinan kekuatan dari ketiga kekuatan tersebut menghasilkan new arising, atau munculnya pembaruan yang bersifat transformatif. Ketiga,apa yang disebut sebagai affirming, denying, dan reconcilling atau neutralizing bukanlah atribut essensial yang permanen namun dapat berubah dan menurut Bourgeault "must be discerned situationally," ${ }^{4}$ arena ketiganya adalah aturan yang fungsional dan bukanlah identitas.Keempat, kemungkinan baru yang disebut sebagai new triad akan muncul tatkala terdapat kondisi netral.

Kelima, tidak semua kategori ketigaan dapat serta-merta mengkonstitusikan Trinitas, dan hanya yang secara dinamis berkelindan seiring persyaratan darithe law of three sajalah yang bisa dianggap sebagai triad atau Trinitas. Pada praktiknya, terdapat static triads yang diilustrasikan melalui percampuranwarna. Misalnya, gabunganwarna merah, kuning, danbiru tidak menghasilkan warna baru, melainkan hanya menghasilkan "mud color," sementara dynamics triad yang meliputi warna merah, kuning, dankuas menghasilkanwarna jingga. Bourgeault menyatakan hanya triad dinamislah yang memenuhi kriteria dalam the law of three untuk disebut sebagai triad yang sesungguhnya.

Keenam, manakala terjadi kebuntuan, maka solusinya adalah mempelajari bagaimana menemukan kekuatan ketiga, yang meskipun tersembunyi, namun selalu ada dalam setiap situasi. Kekuatan ketiga tersebutdisebut Gurdjief tersembunyi tatkala kesadaran kita masih berkutat pada sistem biner yang bersifateither/or. Dengan tekun membangkitkan kesadaran melalui upaya "reorient the mind and strengthen the nervous system," pada gilirannya kitaakan dimampukan untukmendengar vibrasi frekuensi lebih tinggi dari apa yang disebut Gurdjief sebagai the objective truth, yang bisa jadi terletak "somewhere in between". 5

Sebagai sebuah pola, secara esoterik Trinitas memproklamasikan bahwa kemengalirannya merupakan natur ilahi yang secara relasional menyebar dan 
meresapi realitas. Melalui the law of three, Bourgeault mengajak pembacauntuk mencari dan menemukan secara kreatif kekuatan ketiga, untuk selanjutnya beranjak dari pola oposisi biner, demi hadirnya inner \& outer transformation. Secara lugas, Bourgeault menyerukan untuk berhenti bertikai dengan dunia, berhenti bertengkar dengan tubuh, sekularitas, kekacauan, dan melihat denying force atau kekuatan penyangkal sebagai kekuatan yang legitimasi peranannya harus dihargai secara serius. $^{6}$

The law of three mengajak kitauntuk melihat permasalahan dengan cara pandang baru. Ketika Bourgeault menyatakan bahwa, "the opposition is never the problem,"ia menyarankankitauntuk melihat musuh sebagai sebuah peluangdan melihat masalah sebagai sebuah hal yang tidak akan pernah teratasi jika hanya disikapi sekadar dengancaramengeliminasi atau membungkam oposisi. Sebaliknya, masalah dapat teratasi ketika kita bersedia mengkreasi ruang kemungkinan baru (new field of possibility) yang cukup lebar untuk menggenggam ketegangan yang didesakkan oleh oposisi dan meluncurkannya ke arah yang baru. Bourgeault juga mengajak kitauntuk mengakses kekuatan ketiga dengan cermat dan penuh kewaspadaan, supaya kita dapat mendeteksi pola both/and sekaligus melampaui either/or thinking serta menghadirkan kelenturan dalam menghadapi tensi atau ketegangan oposisional. ${ }^{7}$

\section{Metaxu}

Richard Kearney, di dalam karyanya, Strangers, Gods, and Monsters: Interpreting Otherness (2003), memperlihatkan upaya mencari jalan ketiga di tengah konteks binary system. Upaya Kearney dalam mengelaborasi metaxu, yakni sang antara atau jalan tengah (middle way), atau jalan ketiga (third way), menurut saya serupa walau tak sepenuhnya sama dengan gagasan Bourgeault yang mengajak untuk mengakses kekuatan ketiga. Secara ringkas gagasan Kearney saya uraikan sebagai berikut.

Di dalam konteks relasi biner antara "diriku dan liyan" (the one and the others) yang diilustrasikan oleh Kearney sebagai gods and monster, ia ingin menghindari jebakan "judgementalism and relativism". Karena itu, Kearney mengajak pembacanya untuk memperhatikan dan menjalani metaxu, sang antara atau jalan tengah (middle way) yang juga disebutnya sebagai third way, atau jalan 
ketiga. ${ }^{8}$ Jalan ketiga yang dimaksud Kearney ialah menggunakan diacritical hermeneutics dengan tujuan menghadirkan hospitalitas. ${ }^{9}$

Diacritical hermeneutic yang dikembangkan oleh Kearney melalui inspirasi Merleau-Ponty, memiliki karakteristik kritis, kriteriologis, gramatologis, serta diagnosis. ${ }^{10}$ Sebagai sebuah metode, diacritical hermeneutic dapat diimajinasikan sebagai upaya merentangkan tangan ke langit sembari tetap memijakkan kaki di bumi untuk merengkuh sekaligus dimensi sacred dan terrestrial melalui gerakan spiral naik dan turun, "from the highest hintings of the absolute, to the lowest soundings of the abyss." ${ }^{11}$ Diacritical hermeneutics merupakan pilihan hermeneutis Kearney setelah mencermati dua ekstrem yang diperlihatkan oleh hermeneutik romantik dan hermeneutik radikal. Hermeneutik romantik yang disokong oleh Schleiermarker, Dilthey, dan Gadamer dalam konteks friendship, adalah interpretasi filosofis yang berupaya menyatukan kesadaran satu subyek dengan yang lainnya. ${ }^{12}$ Sebaliknya, hermeneutik radikal besutan John Caputo yang diinspirasikan oleh dekonstruksi Derrida, Blanchot, dan Lyotard, sama sekali menolak penyatuan, memegang teguh pada separasi yang muskil direduksi, dan bersikeras dalam memahami natur perubahan yang tidak dapat dimediasi, serta mempertahankan infinite alterity atau perubahan tanpa batas. ${ }^{13}$ Kearney berpendapat bahwa dengan menerapkan diacritical hermeneutics of discernment sebagai metaxu, maka polarisasi antara "diriku dan liyan" dapat terjembatani oleh diriku-sebagai-yang lain, sebagaimana rumusan Kearney berikut:

Between the logos of the One and the anti-logos of the Others, falls the dialogos of oneself-as-another... The basic aim of diacritical hermeneutics of discernment is, I suggest to make us more hospitable to strangers, gods, and monster, without succumbing to mystique or madness. ${ }^{14}$ Kemunculan terminologi hibriditas dilatari oleh eksplorasi Bhabha terhadap relasi kuasa di antara kaum penjajah dan kaum terjajah (colonizer and colonized). Eksplorasi tersebut, dipicu oleh karya Edward Said, Orientalism (1978) yang menganalisis kolonialisasi Barat melalui perspektif linguistik dan kultural untuk kemudian mendeskripsikan Timur atau Orientals, "as exotic, irrational, emotional, etc. and became an image of 'the other' against which Western identity was formed." ${ }^{15}$ Bhabha menemukan bahwa kesalingtergantungan antara penjajah dan terjajah dapat memproduksi hibriditas sebagai ruang ketiga. ${ }^{16}$ Ketika strategi penjajah yang berupaya mentransliterasikan 
identitas kaum jajahan melalui lensa monoscopic gagal, maka lahirlah ruang baru yang dikatakan Bhabha sebagai "something familiar but new." ${ }^{17}$ Ruang baru tersebut ambivalen, liminal, dan familiar, serta berada di antara penjajah-terjajah, lantas kepadanya disematkan nama "hybridity or the third space."18

Menurut Bhabha, hibriditas perlu dipahami secara berbeda dengan multikulturalisme sebab, "hybridity focuses on 'the 'inter' - the cutting edge of translation and negotiation, the in-between space-that carries the burden of the meaning of the culture." ${ }^{19}$ Third space yang disruptif, ambivalent, dan marginal atau liminal ini, bukan hanya menjadi tempat yang memungkinkan pengekspresian identitas saja, melainkan juga menjadi tempat untuk berproses, menciptakan, menegosiasikan, mentransliterasi, dan mentransformasikan identitas. Bhabha menambahkan, "It is in this space that we will find those words with which we can speak of Ourselves and Others. And by exploring this hybridity, this 'Third Space,' we may elude the politics of polarity and emerge as the others of our selves," demikian ungkapnya. ${ }^{20}$

Gagasan Bhabha tentang the in-between space atau third space yang melampaui logika biner, selanjutnya digunakan oleh Christopher Baker dalam konteks teologi praktis untuk mengkonstruksikan hybrid church atau gereja hybrid. ${ }^{21}$ Di dalam gereja hybrid, ketegangan yang ada di antara identitas lokal dan global digenggam. Namun, ketimbang mengkonstruksikan batasan yang rigid dan identitas yang sempit, gereja hybrid lebih memilih untuk membangun blurred identities atau identitas yang kabur. ${ }^{22}$ Menurut Baker, gereja hybrid menempati posisi di ruang hybrid, "in-between solid church and liquid church." ${ }^{23}$ Solid church diasosiasikan dengan institusi, hierarki, dan prosedur formal, sementara liquid church menyandarkan diri pada relasi dan jejaring, bersifat dinamis, serta lentur dalam beradaptasi. ${ }^{24}$

Secara praktis, Baker menjelaskan bahwa gereja hybrid dapat muncul ketika terdapat elemen-elemen yang meliputi: 1) Keterbukaan ruang bagi seluruh anggotanya dan kesediaan membangun koalisi dengan kelompok mitra lain yang berbeda perspektif, 2) mengombinasikan beragam metodologi dan pendekatan secara simultan, 3) siap menanggung risiko dan selalu bereksperimen, 4) meluaskan identitas tanpa meniadakan nilai dan identitas yang telah ada sebelumnya (evolusi, 
bukan revolusi), 4) Being highly reflexive but also strategic, 5) terbuka terhadap tantangan dan suka belajar keterampilan baru. ${ }^{25}$

Berangkat dari gagasan Bhabha dan Baker, Kwok Pui-lan kemudian mengkonstruksikan postcolonial preaching yang dideskripsikan sebagai berikut;

\begin{abstract}
A loccally rooted and globally concious performance that seeks to create a Third Space so that the faith community can imagine new ways of being in the world and encountering God's salvific action for the oppressed and marginalized...Since the aim of postcolonial preaching is to create a subversive Third Space, the preacher must dislodge the audience from the common sense which usually serves the status quo and challenge the legacy of colonialism and the logic of empire. ${ }^{26}$
\end{abstract}

Menurut Kwok Pui-lan, penciptaan third space, atau ruang ketiga, akan memampukan pengkotbah dan pendengar untuk mengimajinasikan cara berada yang baru di tengah dunia, serta discerning anugerah Allah yang dilimpahkan bagi para korban yang termarjinalkan. ${ }^{27}$

Pui-lan mengkritik pola homiletik tradisional. Kritiknya antara lain menyoroti penyampaian khotbah yang kurang melibatkan pendengar, mimbar yang terletak di tempat tinggi sehingga menegaskan distansi, dan penggunaan pakaian jabatan khotbah yang dapat menguatkan kesan clericalismdan separasi. ${ }^{28}$ Pendekatan postcolonial preaching yang mengedepankan multivoiced, dialogical and polycentric, mengajak kita untuk memahami khotbah bukan sekadar sebagai penyampaian pesan satu arah (transmisi) dari pengkhotbah kepada pendengar, sebagaimana lazimnya teori homiletik tradisional yang dikecam Pui-lan sebagai representasi Eurosentris, melainkan lebih melihat khotbah sebagai sebuah peristiwa komunal. ${ }^{29}$ Di dalam ruang ketiga, semua diundang untuk terlibat, berpartisipasi, dan merayakan ruang antara (inter) yang terdapat pada identitas, bahasa, dan kultur. ${ }^{30}$ Menariknya, sebagai salah satu implikasi, Pui-lan menyarankan adanya pembagian tanggung jawab untuk berkhotbah, yang sebaiknya bukan didominasi oleh pendeta saja melainkan juga menjadi tanggung jawab pemimpin jemaat awam (penatua dan diaken), atau warga yang telah dilatih dan dibekali dengan ilmu berkotbah. Sebab, menurut Pui-lan, "In a reversal of empire, those who are not given 
voice by society should be given the space and be empowered to share their stories and God's action in their midst.",31

\section{Menakar persamaan dan perbedaan metaxu, third space dan third force}

Demikianlah sekilas gagasan metaxu, atau jalan tengah Kearney, dan inbetween atau third space Bhabha, yang kemudian diadopsi oleh Baker serta Kwok Pui-lan, dan memiliki kemiripan dengan ajakan Bourgeault untuk mengakses third force, atau kekuatan ketiga. Kendati demikian, terdapat perbedaan di antara ketiganya, yakni bahwa Kearney dan Bhabha, berikut Baker dan Pui-lan, sama sekali tidak mendudukkan konsep yang mereka konstruksikan pada basis Trinitas sebagaimana yang telah dilakukan oleh Bourgeault.

Richard Kearney menggunakan diacritical hermeneutics dalam rangka menemukan metaxu dan tampak fokus ke dalam narasi diri untuk mengingat dan menemukan sisi lain di dalam "diriku sendiri". ${ }^{32}$ Dengan cara itu, Kearney menemukan diriku-sebagai-yang-lain sebagai jalan tengah yang merespons kontestasi diri dan liyan. Menurut saya, jalan tengah Kearney tetap mengutamakan "diriku” sebagai kekuatan yang mendominasi. Padahal, jika merujuk pada aturan the law of three, kekuatan ketiga (reconciling) posisinya setara, sejajar, dan sama pentingnya dengan kedua kekuatan yang lain (affirming, denying). Di dalam konteks pertikaian antara "diriku (affirming) dan liyan (denying)," kekuatan ketiga idealnya tidak diletakkan pada diriku-sebagai-yang-lain, karena hal tersebut menegaskan kembali oposisi biner, sekaligus berarti bahwa "diriku" sebagai affirming factor menjadi jauh lebih dominan ketimbang yang lain.

Bhabha tampak fokus pada eksplorasi perjumpaan dan persilangan di ruang antara, atau the in-between space, yang memungkinkan Baker untuk mendapatkan inspirasi dalam mengkonstruksi gereja hybrid dan blurred identity. Di dalam the law of three, kekuatan ketiga memang dapat dijumpai di ruang antara, tetapi sekaligus tidak selalu berada di ruang antara. Berbeda dengan gagasan Bhabha, kekuatan ketiga di dalam prinsip pertama skema the law of three yang digagas oleh Bourgeault bukanlah produk dari intersection atau persilangan di antara oposisi (Bourgeault 2013, 25-37). Di dalam aturan the law of three, static triad seperti warna merah, kuning, danbiru tidak menghasilkan warna baru, namun hanya menghasilkan "mud color" yang identitasnya kabur. Hanya dynamics triad yang meliputi kriteria warna merah, kuning, dankuas sajalah yang dapat menghasilkanwarna baru, yakni warna 
jingga. Oleh karena itu, kata kunci yang harus digarisbawahi adalah menemukan reconciling atau neutralizing factor sebagai kekuatan ketiga, supaya ketiga kekuatan (affirming, denying, reconciling atau neutralizing) menjadi utuh dan dapat menghadirkan new transformative arising. ${ }^{33}$

Menurut Bhabha, the in-between space, atau third space sebagai ruang untuk menegosiasikan identitas dan menerbitkan inisiatif sosio-politik, memilikikarakteristik yang lekat dengan pembebasan dari jajahan kultural serta mengguncangkan hegemoni. ${ }^{34}$ Bagi saya, gagasan Bhabha positif dan dapatditerima dalam konteks misi gereja. Namun, bagaimana pun, watak third space atau ruang ketiga yang ofensif berbeda dengan watak third force atau kekuatan ketiga yang rekonsiliatif. Konsekuensinya, jika ditarik untuk merespons proposal Baker, kita dapat mempertanyakan apakah hybrid church dan blurred identity yang diusung Baker sebagai third space sebenarnya telah menjalankan fungsi rekonsiliatif yang menetralisasi oposisi biner antara solid church dan liquid church? Bagaimana jika hybrid church dan blurred identity hanya sekadar konstruksi yang mencampurbaurkan warna, bermain pada wilayah gradasi sehingga memperkeruh situasi dan mengancam kedua kekuatan lainnya? Lantas yang terpenting adalah, dapatkah hybrid church sebagai third space, bersama solid church dan liquid church, menghasilkan new transformative arising? Izinkan pertanyaan-pertanyaan yang mengkritisi proposal Baker tersebut menjadi open-ended question, atau pertanyaan terbuka yang akan menarik jika dibahas secara khusus dalam tema dan kesempatan yang lain.

Gagasan Kwok Pui-lan dalam postcolonial preaching yang mengajak kita untuk menaruh perhatian terhadap suara pinggiran dalam konteks kotbah sangatlah penting. Kwok Pui-lan fokus pada upaya menciptakan ruang ketiga di dalam peribadatan yang bersifat plurivocal-dialogical dan menantang homiletik tradisional yang ditudingnya sebagai yang bersifat Eurosentris. ${ }^{35}$ Namun, menurut saya tantangan tersebut bermasalah, sebab di dalam prinsip the law of three, ketiga kekuatan yakni affirming, denying, dan reconciling, setara serta tidak ada yang mengatasi, atau menempati posisi yang lebih unggul ketimbang yang lain. ${ }^{36}$ Jika gagasan Kwok Pui-Lan tentang penciptaan third space atau ruang ketiga malah terjerumus dalam logika biner yang mempertentangkan antara postcolonial preaching dengan homiletik tradisional, sebaliknya, third force atau kekuatan ketiga 
di dalam pemahaman the law of three justru mengedepankan rekonsiliasi, yang melampaui oposisi biner.

\section{KESIMPULAN}

Demikianlah dapat disimpulkan bahwa metaxu, yakni sang antara, atau jalan tengah, third space atau ruang ketiga, dan third force atau kekuatan ketiga, memiliki kemiripan karena ketiganya sama-sama bertujuan untuk merespons binary system. Namun, biarpun demikian, metaxu, third space, dan third force, ternyata tak sepenuhnya serupa dan memiliki perbedaan.Gagasan Kearney tentang metaxu berbeda dengan ide Bourgeault mengenai third force atau kekuatan ketiga, karena Kearney menaruh tekanan secara berat sebelah terhadap "diriku” sebagai kekuatan pertama. Padahal di dalam the law of three, ketiga kekuatan keberadaannya setara. Selain itu, third space atau ruang ketiga konstruksi Bhabha berwatak ofensif, ambivalen, blurred, disruptif, dan selalu menantang dominasi kekuatan yang lain. Sementara, menurut Bourgeault, di dalam prinsip the law of three, third force atau kekuatan ketiga berwatak rekonsiliatif, menetralisasi pertikaian, dan merengkuh.

\section{Endnotes :}

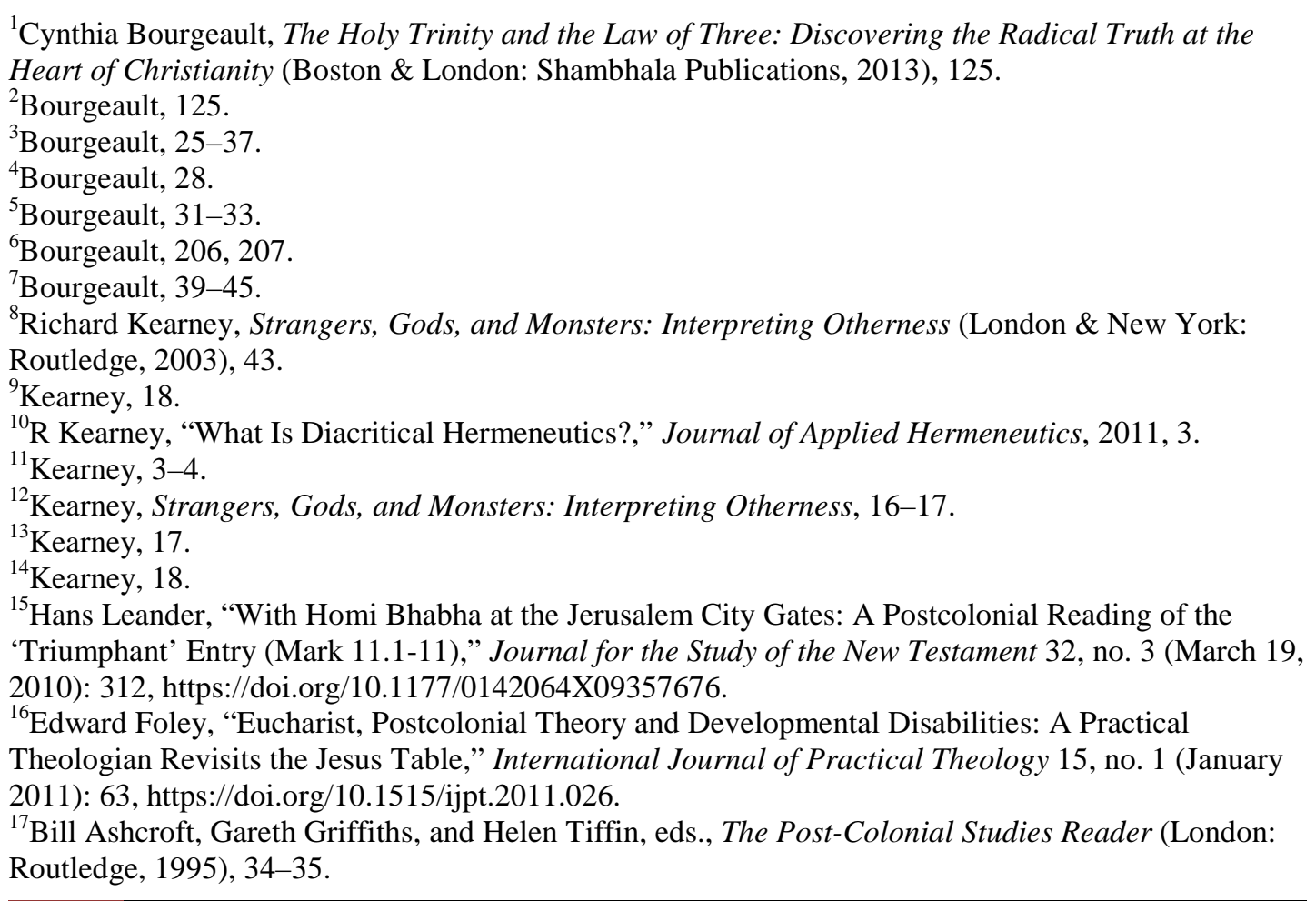




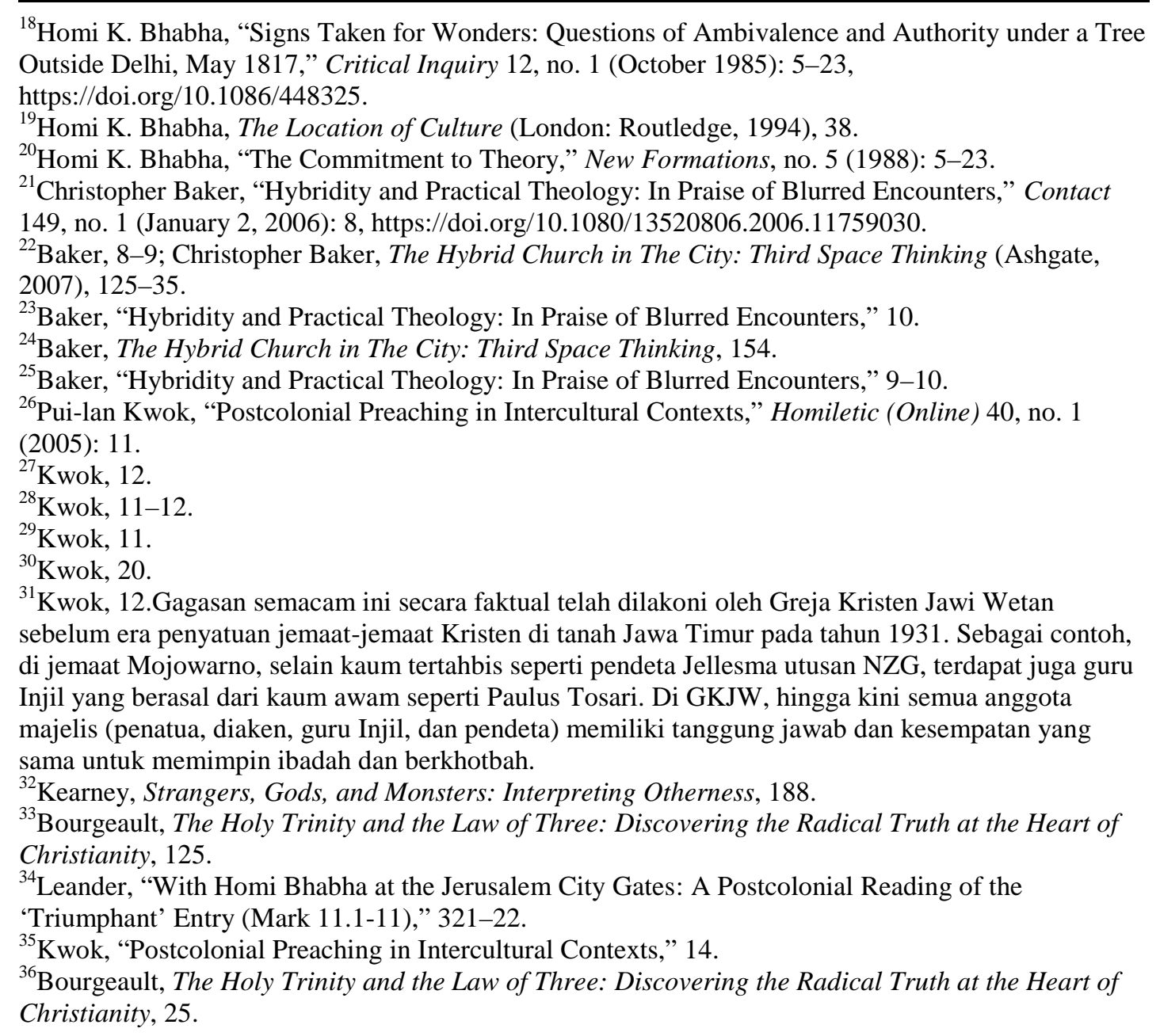

\section{DAFTAR PUSTAKA}

Ashcroft, Bill, Gareth Griffiths, and Helen Tiffin, eds. The Post-Colonial Studies Reader. London: Routledge, 1995.

Baker, Christopher. "Hybridity and Practical Theology: In Praise of Blurred Encounters." Contact 149, no. 1 (January 2, 2006): 5-11. https://doi.org/10.1080/13520806.2006.11759030.

- The Hybrid Church in The City: Third Space Thinking. Ashgate, 2007.

Bhabha, Homi K. "Signs Taken for Wonders: Questions of Ambivalence and Authority under a Tree Outside Delhi, May 1817." Critical Inquiry 12, no. 1 (October 1985): 144-65. https://doi.org/10.1086/448325. 
- "The Commitment to Theory." New Formations, no. 5 (1988).

- The Location of Culture. London: Routledge, 1994.

Bourgeault, Cynthia. The Holy Trinity and the Law of Three: Discovering the Radical Truth at the Heart of Christianity. Boston \& London: Shambhala Publications, 2013.

Foley, Edward. "Eucharist, Postcolonial Theory and Developmental Disabilities: A Practical Theologian Revisits the Jesus Table." International Journal of Practical Theology 15, no. 1 (January 2011). https://doi.org/10.1515/ijpt.2011.026.

Kearney, R. "What Is Diacritical Hermeneutics?” Journal of Applied Hermeneutics, 2011, 14.

Kearney, Richard. Strangers, Gods, and Monsters: Interpreting Otherness. London \& New York: Routledge, 2003.

Kwok, Pui-lan. "Postcolonial Preaching in Intercultural Contexts." Homiletic (Online) 40, no. 1 (2005): 8-21.

Leander, Hans. "With Homi Bhabha at the Jerusalem City Gates: A Postcolonial Reading of the 'Triumphant' Entry (Mark 11.1-11)." Journal for the Study of the New Testament 32, no. 3 (March 19, 2010): 309-35. https://doi.org/10.1177/0142064X09357676. 